\title{
Programmed cell death in Saccharomyces cerevisiae is hampered by the deletion of GUP1 gene
}

\author{
Joana Tulha, Fábio Faria-Oliveira, Cândida Lucas and Célia Ferreira*
}

\begin{abstract}
Background: During the past years, yeast has been successfully established as a model to study mechanisms of programmed cell death regulation. Saccharomyces cerevisiae commits to cell death showing typical hallmarks of metazoan apoptosis, in response to different stimuli. Gup1p, an O-acyltransferase, is required for several cellular processes that are related to apoptosis development, such as rafts integrity and stability, lipid metabolism including GPI anchor correct remodeling, proper mitochondrial and vacuole function, bud site selection and actin dynamics. Therefore, we hypothesize that apoptotic process would be affected by GUP1 deletion.

Results: In the present work we used two known apoptosis inducing conditions, chronological aging and acetic acid, to assess several apoptotic markers in gup $1 \Delta$ mutant strain. We found that this mutant presents a significantly reduced chronological lifespan as compared to $\mathrm{Wt}$ and it is also highly sensitive to acetic acid treatment. In addition, it presents extremely high levels of ROS. There were notorious differences on apoptotic markers between Wt and gup $1 \triangle$ mutant strains, namely on the maintenance of plasma membrane integrity, on the phosphatidylserine externalization, on the depolarization of mitochondrial membrane and on the chromatin condensation. Those suggested that the mutant, under either condition, probably dies of necrosis and not from apoptosis.
\end{abstract}

Conclusions: To Gup1p has been assigned an important function on lipid rafts assembly/integrity, lipid metabolism and GPI anchor remodeling. Our results provide, for the first time, the connection of the integrity of yeast lipid rafts and apoptosis induction and/or signaling, giving new insights into the molecular mechanisms underlying this process in yeast.

\section{Background}

Apoptosis is the most common process of programmed cell death (PCD) in eukaryotes. It is vital for the fast elimination of useless or injured cells, and for the differential development of tissues and organs. In humans the malfunction of this process leads to severe diseases, namely neurodegenerative disorders, AIDS and cancer. The existence of PCD processes in lower eukaryotes or bacteria was for long disregarded due to the absence of obvious benefits for unicellular organisms. Nonetheless, numerous works contributed to evidence $\mathrm{PCD}$ occurring in single cell organisms [1-4], as well as to the establishment of yeast as a

*Correspondence: celiamjf@gmail.com

CBMA (Centre of Molecular and Environmental Biology), Department of Biology, University of Minho, Campus de Gualtar, 4710-057 Braga, Portugal good model to study mechanisms of apoptotic regulation [5,6]. Multicellular aggregates of microbial cells, like colonies or biofilms, are spatially organized and require the specialization of cells differentially localized to ensure supply of nutrients and water to the whole cell ensemble [7]. The growing concept that microbial multicellular aggregates form functional and higher organized structures, as a kind of proto-tissue, supports the notion that PCD may be a much more spread and conserved mechanism of cellular altruistic behaviour.

The characteristic apoptotic markers, as DNA fragmentation, phosphatidylserine externalization, chromatin condensation, release of cytochrome $C$, and/or caspases activation are also valid to assess apoptotic yeast cells $[1,8]$. Furthermore, an increasing list of homologues of

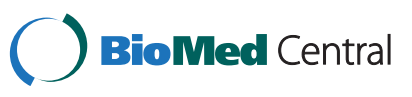


apoptotic regulators in metazoans has been identified in yeast, such as Ycalp, the proposed yeast caspase [9]; Aifp, the apoptosis inducing factor [10]; EndoG, an endonuclease which regulates not only life but also death in yeast [11]; Nma111p, a yeast HtrA-like protein [12]; Bir1p, an inhibitor-of-apoptosis protein [13] and Ybh3p, a yeast protein that interacts with $\mathrm{Bcl}-\mathrm{xL}$ and harbours a functional BH3 domain [14]. Additionally, the expression in S. cerevisiae of the mammalian Bcl-2 family and PKC isoforms [15], led to the same phenotypes observed in mammalian cells, providing evidence that apoptosis is an evolutionarily conserved mechanism. Several agents can induce yeast $\mathrm{PCD}$, like hydrogen peroxide, UV radiation, the absence of nutrients, hyper-osmotic stress, acetic acid [8] and aging [6]. Aging in yeast can be studied assessing either replicative or chronological lifespan. Replicative lifespan is defined as the number of daughter cells a single yeast mother cell produces before senescence; chronological lifespan is defined by the length of time cells can survive in a non-dividing, quiescence-like state [16]. Chronological aged yeast cells also exhibit typical apoptotic markers. During chronological aging, the old yeasts die and release certain substances (nutrients) into the medium in order to promote survival of other aged cells, yet fitter ones [6].

On the other hand, it has been demonstrated that apoptotic S. cerevisiae cells display changes in the expression of some genes associated with the sphingolipids metabolism [17], which is consistent with changes in the proportions of the various sphingolipid types in dying cells [18]. Carmona-Guitierrez and co-authors [19] observed the apoptosis induction by external addition of C2-ceramide, whereas Barbosa and co- authors reported changes in sphingolipids during chronological aging, namely a decrease of dihydrosphingosine levels and an increase of dihydro- $C(26)$-ceramide and phyto- $C(26)$ -ceramide levels [20]. Also, a role in apoptosis and aging of Ydc1p ceramidase was described [18], and a yeast homologue of mammalian neutral sphingomyelinase 2 was associated with apoptosis [21]. Moreover, some intermediates in sphingolipids biosynthesis act as signalling molecules and growth regulators [22,23]. Nevertheless, modest attention has been paid to the involvement of sphingolipids in yeast PCD.

In S. cerevisiae, sphingolipids are mainly located in the plasma membrane, being more concentrated along the sphingolipid-sterol rich domains [24], commonly named rafts. These domains play fundamental roles in connecting the plasma membrane to the cytoskeleton, ER and Golgi, and therefore in the correct protein sorting and trafficking through exocytosis/endocytosis [25]. Moreover, rafts harbour signalling molecules besides sphingolipids, like kinases, PI2P (phosphatidylinositol-3,4-diphosphate), and GPI (glycosylphosphatidylinositol)-anchored proteins
[25,26]. The latter, are proteins attached to the plasma membrane via a lipid anchor that contains either a ceramide or diacylglycerol [27]. Gup1p is a membrane-bound $O$-acyltransferase [28,29] involved in lipid metabolism, rafts integrity and assembly [30] and GPI anchor remodelling [31]. This protein was primarily identified associated with phenotypes on glycerol metabolism and transport [32], but has further been implicated in a vast number of distinct processes, namely cell wall structure, composition and biogenesis [33], plasma membrane assembly and composition [30,34], cytoskeleton polarization and bud site selection [35], and telomere length [36], all of which directly or indirectly associated with apoptosis. This work presents evidence that cells lacking GUP1 are not able of undergoing apoptosis, as revealed by the analysis of several apoptotic markers (mainly lack of membrane integrity and of phosphatidylserine externalization). Instead the mutant appears to be experiencing a necrotic cell death process, upon both chronological aging and acetic acid induction. This result adds to the growing view that as in higher eukaryotes, lipids are involved in signalling PCD in yeast.

\section{Results}

GUP1 is involved in a wide range of cellular processes, some of which are associated directly or indirectly with apoptosis, such as rafts integrity and lipids metabolism $[17,18,21,30,31,34]$, cytoskeleton polarization [35,37], and telomere length $[36,38]$. In the present work, we assess apoptotic markers for gup $1 \Delta$ mutant strain and compare them with $\mathrm{Wt}$, under two different conditions documented to induce apoptosis in yeast: chronological aging and acetic acid [8,39].

\section{gup 1 $\Delta$ mutant cells exhibit a reduction in chronological lifespan}

Yeast chronological lifespan is described as the length of time a population remains viable in the non-dividing/stationary phase $[40,41]$. Chronologically aged yeast cells die exhibiting specific markers of apoptosis [6,40]. We checked the survival of gup $1 \Delta$ chronologically aged cells in comparison to $\mathrm{Wt}$, continuously for 30 days throughout stationary phase until complete death of the culture.

The growth curve (Figure 1 insert) showed an apparent similar growth rate for both strains during exponential phase, as well as an almost coincident transition to diauxic and stationary phases. On the other hand, the survival curve (Figure 1) showed that gup1 $1 \Delta$ mutant cells died considerably sooner than Wt. After day 3 the survival rate of gup $1 \Delta$ mutant started to decrease, reaching $50 \%$ around day 7 , and in day 11 we observed that only a small number of gup1 $1 \Delta$ mutant cells stayed alive. Conversely, Wt strain begins to die around day 8 , reaches $50 \%$ survival at day 12 and on day 19 the culture was practically dead. 


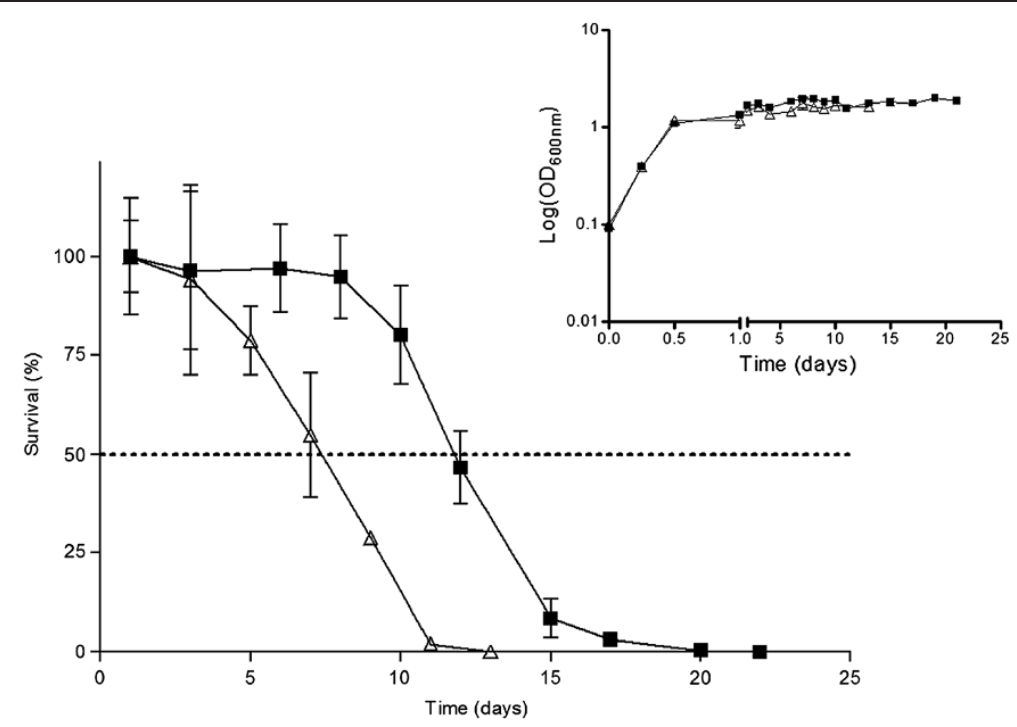

Figure 1 Deletion of GUP1 decreases chronological lifespan. Wt $(\mathbf{-})$ and gup $1 \triangle$ mutant $(\triangle)$.cells were inoculated in YNB medium and survival monitored by c.f.u. for 30 days (100\% represents the 1,000 plated cells counting using a Neubauer chamber). The growth curve in YNB for both strains is presented in the insert. Data represent mean \pm SD of at least 3 independent experiments.

\section{Chronological aged gup $1 \Delta$ mutant seems to be incapable of dying by apoptosis but rather by necrosis}

In order to investigate whether chronologically aged $\mathrm{Wt}$ and gup $1 \Delta$ mutant cells die by apoptosis, we analyzed several apoptotic markers in exponentially growing and chronologically aged cultures on both strains [6,42]. We choose 6 hours growth to assess exponential cells, and day 7 or day 12 to test chronologically aged cells of gup1 1 mutant and $\mathrm{Wt}$, respectively.

In yeast, as in mammalian cells, the maintenance of plasma membrane integrity during cell death is an indicator of apoptosis. In this work, we evaluated the integrity of plasma membrane, in exponential and aged Wt and gup $1 \Delta$ mutant strains, by PI staining. In gup $1 \Delta \mathrm{mu}-$ tant, we observed a substantial increase in the number of cells stained with PI over time, until every cell presented PI positive. Still, although the pattern is identical, in Wt the percentage of PI positive cell was proximally 2-fold less (Figure 2A). Yet, the percentages of PI positive cells can be over evaluated since apoptotic cells can become leaky during further cultivation, increasing PI positives. To distinguish this secondary necrosis from primary necrosis further tests were performed.

Phosphatidylserine has an asymmetric distribution in the lipid bilayer of the cytoplasmic membrane [43]. The exposure of phosphatidylserine at the outer surface of the cytoplasmic membrane occurs at the early stages of apoptosis [44], when membrane integrity is still retained. We checked this through the FITC-coupled Annexin V reaction followed by flow cytometry of co-labeled Annexin V/ PI cells. We observed that gup $1 \Delta$ mutant aging cells presents a significant percentage (53\%) of necrotic cells
(Ann $(-) / \mathrm{PI}(+))$. In contrast, in Wt cells the exposure of phosphatidylserine (Ann $(+) /$ PI $(-))$ increased in aged cells (less than $1 \%$ to $12 \%$ ) (Figure $2 \mathrm{~B}$ ).

In order to evaluate the mitochondrial membrane depolarization, $\mathrm{DiOC}_{6}$ was used. At a concentration of $20 \mathrm{ng} / \mathrm{ml}$ this dye accumulates specifically at mitochondrial membranes and can be observed by fluorescence microscopy. Nonetheless, cells that have low mitochondrial membrane potential will fail to accumulate $\mathrm{DiOC}_{6}$ [37]. Both gup1s mutant and Wt exponential cells stained with $\mathrm{DiOC}_{6}$ revealed intact mitochondrial networks, confirming a normal polarization of mitochondrial membranes (Figure 2C left panels). Aged cells (7 and 12 days in gup1 1 mutant and $\mathrm{Wt}$, respectively), showed a decrease in green fluorescence of approximately $40 \%$ in Wt and 50\% in gup $1 \Delta$ mutant, reflecting a reduction in mitochondrial membrane potential (Figure 2C right panels). Moreover, some cells exhibited a strong green fluorescence all over the cell, mainly in gup1 1 mutant strain, suggesting that these cells possibly had the plasma membrane altered, which in turn resulted in the accumulation of $\mathrm{DiOC}_{6}$ on the cytosol (Figure 2C right panels).

Finally, we evaluated chromatin condensation through DAPI staining (Figure 2D). Moderate chromatin condensation upon DAPI staining was observed in $80 \%$ of old gup1 1 mutant cells, which can be visualized by the fluorescent semicircles formed by the chromatin fragments (Figure 2D right panels). Regarding Wt aged cells, we observed some cells with chromatin condensation, but we also detected cells without stained nucleus or even with multiples nucleus (Figure 2D right panels). These 

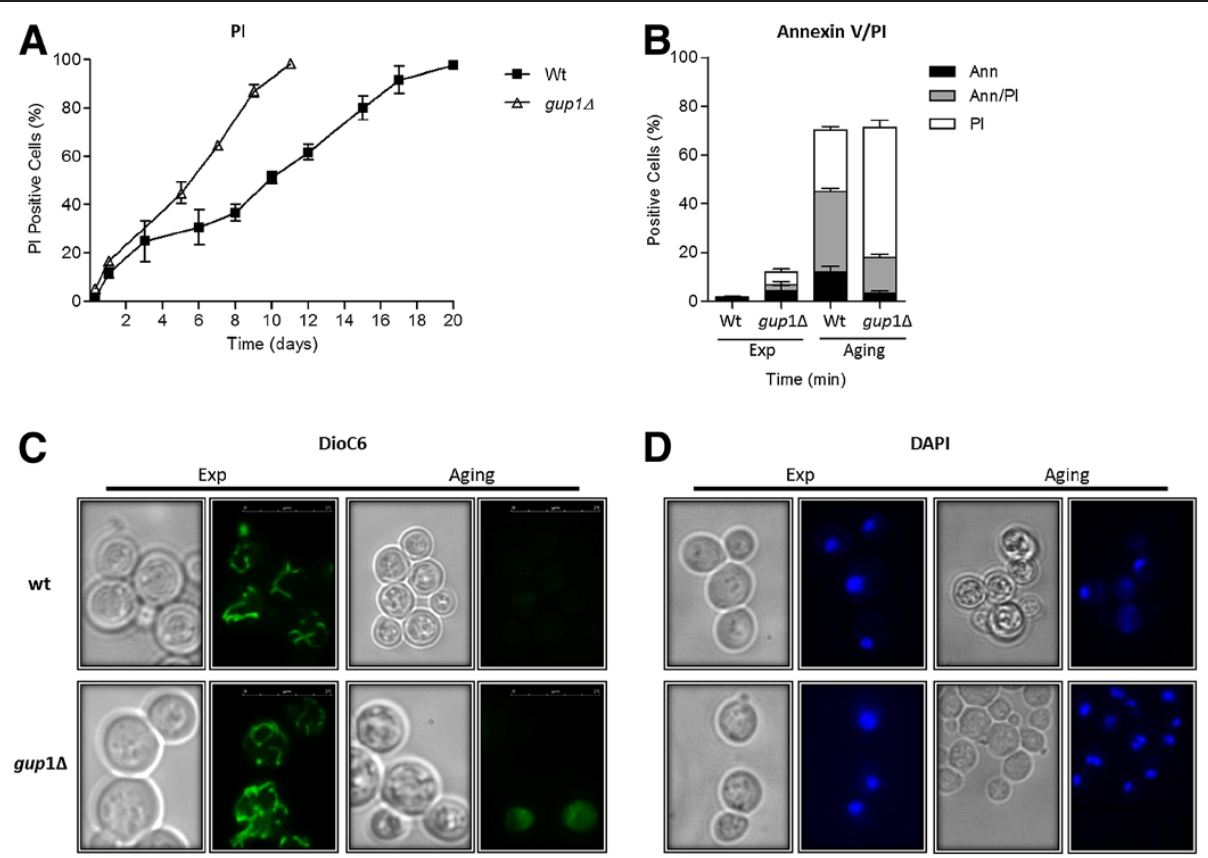

Figure 2 Analysis of apoptotic markers in Wt and gup $1 \Delta$ chronologically aged cells. (A) Graphic representation of the percentage of cells displaying positive PI staining. (B) Phosphatidylserine externalization assessed by cytometric analysis of Annexin $V$ labelling. Graphic representation of the percentage of cells displaying Ann V (+)/PI (-) (black bars), Ann V(+)/PI (+) (grey bars) and Ann V(-)/PI (+) (white bars). (C) Representative photos of $\mathrm{DiOC}_{6}$ staining exponential phase and aged cells. (D) Representative photos of DAPI staining of exponential phase and aged cells. For flow cytometry and fluorescence microscopy assays a minimum of 35,000 and 300 cells were counted, respectively. Data represent mean \pm SD of 3 independent experiments.

are probably due to an endomitosis process $[45,46]$. In contrast, in exponentially growing cultures, both Wt and gup1s mutant cells presented integral chromatin mirrored as single round fluorescent circles in the middle of the cell (Figure 2D left panels).

\section{gup $1 \Delta$ mutant cells are sensitive to acetic acid}

In a previous work, it was described that gup $1 \Delta$ mutant cells were sensitive to weak acids [33]. However, the concentrations of acetic acid that induce apoptosis in yeast are considerably higher than the ones studied at that time $(50 \mathrm{mM})$. Therefore, we investigated gup $1 \Delta$ mutant and Wt sensitivity to a wide range of acid concentrations (50, 80 and $100 \mathrm{mM}$ ). With the lowest concentration of acetic acid $(50 \mathrm{mM})$, no effect was observed; however, when the concentration was increased both strains were affected, being gup1s mutant strain the most sensitive one. At the highest concentration tested, $100 \mathrm{mM}$ of acetic acid, the difference between the two strains was more obvious, with gup $1 \Delta$ mutant showing growth only until the second dilution, whereas Wt presents growth up to the fourth dilution (Figure 3A). Additionally, we determined the death kinetics of both strains treated with $160 \mathrm{mM}$ of acetic acid (Figure 3B), as commonly assayed to evaluate apoptosis induced by acetic acid [4]. For that, Wt and gup1s mutant cells at exponential growth phase were exposed to acetic acid, and the survival rate measured by c.f.u. counts. In both cases, the yeast cells died in response to acetic acid, but the cell death patterns were different. Until $60 \mathrm{~min}$ of acetic acid treatment, no significant difference was found between Wt and gup $1 \Delta$ mutant strains, presenting around 90\% and $85 \%$ cell viability, respectively. These percentages progressively decreased in both strains, being this reduction more accentuated in the gup $1 \Delta$ mutant strain. After $120 \mathrm{~min}$ in the presence of acetic acid, only $15 \%$ of gup1 $1 \Delta$ mutant cells remained alive, whereas Wt presented a survival rate of around $75 \%$. At the last timepoint analyzed, $180 \mathrm{~min}$, the dissimilarity among strains sharpened up; only a few cells of gup $1 \Delta$ mutant strain were viable, whereas $\mathrm{Wt}$ strain displayed a survival rate of around 55\% (Figure 3B).

Acetic acid induces cell death by necrosis similar to that triggered by chronological aging in the gup $1 \Delta$ mutant strain

In order to assess whether cell death induced by acetic acid treatment followed a programmed process of apoptosis, we analyzed several apoptotic markers. The first marker analyzed was PI staining to estimate the loss of membrane integrity. Acetic acid treatment led to a pronounced increase of gup1 $1 \Delta$ mutant PI positive cells, 

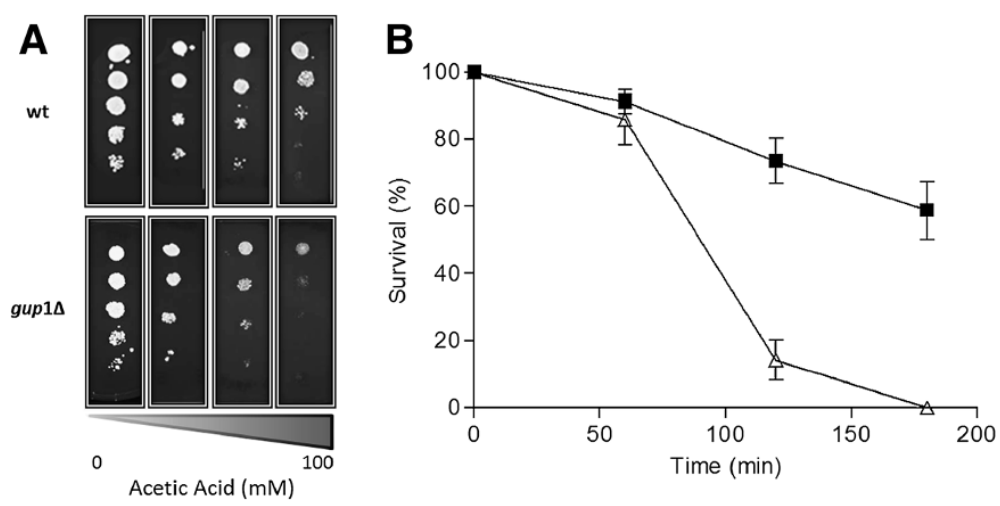

Figure 3 Loss of GUP1 confers sensitivity and reduces survival in presence of acetic acid. (A) Sensitivity of Wt and gup $1 \triangle$ mutant cells to several increasing concentrations of acetic acid by Dropout assay. Cultures were grown to mid-exponential phase in YNB medium, and ten-fold serial dilutions were spotted onto YNB plates supplemented with acetic acid. All plates were incubated at $30^{\circ} \mathrm{C}$ for $48 \mathrm{~h}$. (B) Survival curve of Wt (-) and gup $1 \Delta(\Delta)$ cultures during acetic acid treatment. Exponential cells were treated with $160 \mathrm{mM}$ acetic acid for 180 min and viability determined by c.f.u. at the indicated time points (100\% survival corresponds to the total c.f.u. at time zero). Data represent mean \pm SD of at least 3 independent experiments.

reached nearly $100 \%$ after 180 min of treatment, while in the Wt strain this percentage did not exceed $10 \%$ (Figure 4A). In addition, we examined the phosphatidylserine exposure by simultaneously FITC- coupled Annexin V/PI staining (Figure 4B). Similarly to what was observed with the aging experiment, a substantial increase $(72 \%)$ in necrotic cells $($ Ann $(-) / \mathrm{PI}(+))$ were observed after treatment with acetic acid (180 min treatment). In opposition, Wt strain presents an increase $(8 \%)$ in apoptotic cells (Ann $(+) / \mathrm{PI}(-))$ after the treatment with acetic acid (Figure 4B).

Yeast mitochondria undergo both structural and functional changes after the incubation with acetic acid [47], including mitochondrial membrane depolarization. In
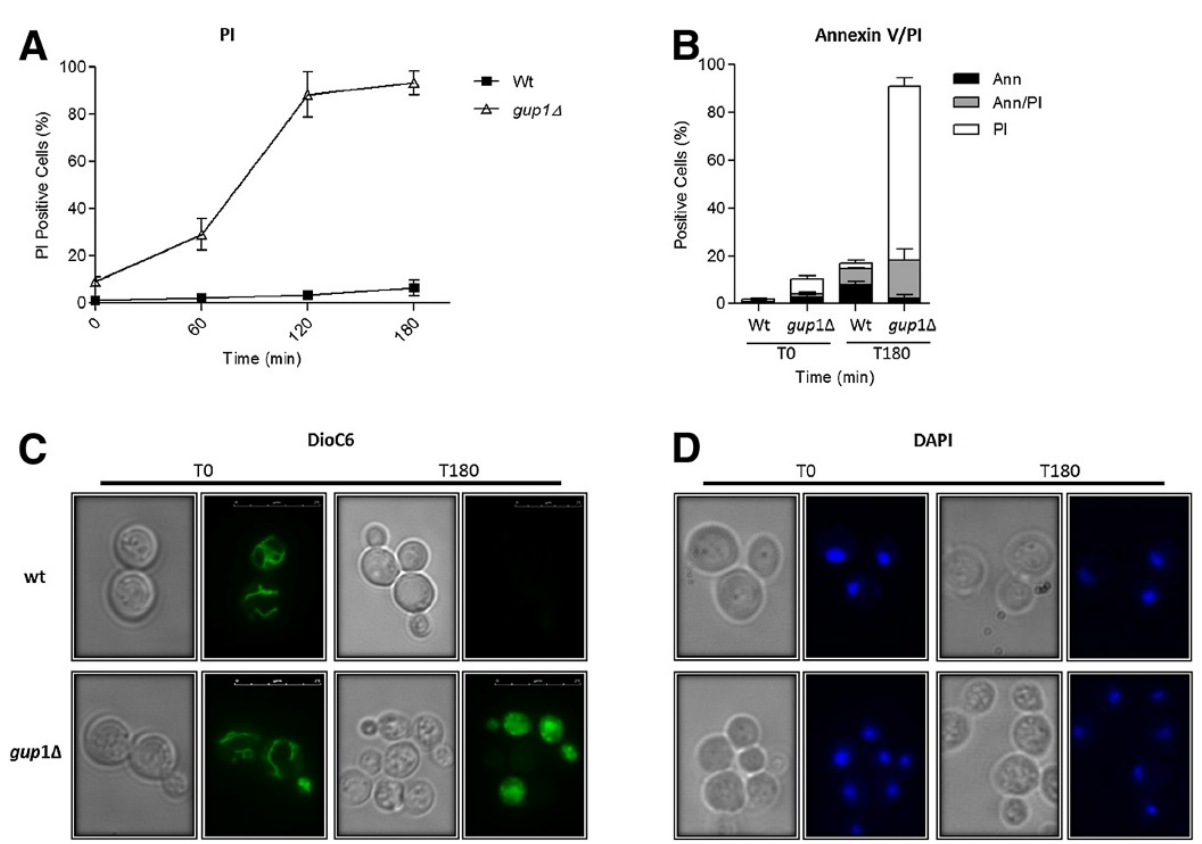

Figure 4 Analysis of apoptotic markers in cells treated with acetic acid. Wt and gup $1 \Delta$ mutant cells were exposed to $160 \mathrm{mM}$ acetic acid for $180 \mathrm{~min}$. (A) Graphic representation of the percentage of cells displaying positive PI staining. (B) Phosphatidylserine externalization assessed by cytometric analysis of Annexin V labelling. Graphic representation of the percentage of cells displaying Ann $V(+) / P I(-)($ black bars), Ann V(+)/PI $(+)$ (grey bars) and Ann V(-)/PI (+) (white bars). (C) Representative photos of DiOC 6 staining untreated cells and cells after 180 min at acetic acid treatment. (D) Representative photos of DAPI staining untreated cells and after 180 min acetic acid treatment. For flow cytometry and fluorescence microscopy assays a minimum of 35,000 and 300 cells were counted, respectively. Data represent mean \pm SD of 3 independent experiments. 
order to evaluate this phenomenon, $\mathrm{DiOC}_{6}$ staining was used to visualize mitochondrial membranes (Figure 4C). Just before apoptosis induction with acetic acid, most of Wt and gup $1 \Delta$ mutant cells presented intact mitochondrial networks (Figure 4C left panels). After the treatment, it was possible to visualize depolarization of mitochondrial membranes in approximately $40 \%$ and $30 \%$ of gup $1 \Delta$ mutant and Wt cells, respectively, mirrored by the absence of fluorescence (Figure 4C right panels). Furthermore, we observed a considerable number of gup1s mutant cells displayed an increase in $\mathrm{DiOC}_{6}$ green fluorescence, similarly to the results obtained when the apoptotic inductor was chronological aging (Figure $4 \mathrm{C}$ right panels).

Additionally, we checked for chromatin condensation during acetic acid treatment by staining cells with DAPI (Figure 4D). Nearly no chromatic condensation was observed in both gup1 $1 \Delta$ mutant and Wt untreated cells, as reflected by the single round fluorescent circles in the center of the cells (Figure 4D left panels). Yet, after the treatment with acetic acid, we observed a significant increase in gup1 $\Delta$ mutant cells exhibiting moderate chromatin condensation along the nuclear envelope ( $90 \%)$. In Wt, $\sim 25 \%$ of cells presented chromatin condensation (Figure 4D right panels).

\section{gup $1 \Delta$ mutant cells accumulate large amounts of ROS} during chronological aging and acetic acid treatment It is well documented that the loss of mitochondrial membrane potential can lead to increased production of ROS in higher eukaryotes, which is seen as an apoptoticrelated process in yeasts $[3,46]$. On the other hand, several points of evidence indicate that, in yeast, the accumulation of ROS is a major factor determining aging $[48,49]$ and triggering PCD $[3,39,50]$. The accumulation of ROS is commonly measured by incubating cells with dihydroethidium (DHE), which is oxidized (by ROS) to the ethidium. ROS were measured on both chronologically aged and acid acetic treated gup $1 \Delta$ mutant and Wt cells. Regarding chronological assay, this covered exponential, stationary and death phases (Figure 5A). A significantly higher increase of ROS levels over time was observed in gup1 $1 \Delta$ mutant in comparison to Wt cells. The biggest difference was on day 6 (stationary phase), when the percentage of gup1 $1 \Delta$ mutant cells exhibiting ROS accumulation was the twice $(\sim 80 \%)$ that of Wt cells ( $40 \%)$. The mutant reached $100 \%$ of cells with ROS accumulation on day 10 , while $\mathrm{Wt}$ took 17 days to reach that state (Figure 5A). Still regarding gup $1 \Delta$ mutant, the $100 \%$ ROS was maintained till the end of experiment (more five days), which is in agreement with the observed death of these strain cells (Figure 1 - after 12 days more than $99 \%$ death). The difference between $\mathrm{Wt}$ and gup $1 \Delta$ mutant strains was also extremely notorious in acetic acid treated cells (Figure 5B). Soon after acetic acid addition, gup1 $1 \Delta$ mutant exhibited ROS accumulation in $\sim 8 \%$ of the cells, whereas Wt presented less than $1 \%$. This difference was accentuated with time. At one hour treatment gup1D mutant cells with ROS accumulation was higher than $30 \%$ and Wt cells less than $5 \%$. Two hours treatment led to a substantial rise of ROS positive gup $1 \Delta$ mutant cells ( 85\%) compared with only $\sim 10 \%$ of Wt. At the end of the treatment, almost all gup1A mutant cells exhibited ROS accumulation, in clear contrast with the $\sim 15 \%$ of ROS accumulation displayed by Wt strain (Figure $5 \mathrm{~B}$ ).

\section{Discussion}

The finding of an endogenous PCD process with an apoptotic phenotype has turned yeast into a powerful model for apoptosis research $[39,51,52]$. In fact, S. cerevisiae commits to cell death showing typical features of mammalian apoptosis, in response to different stimuli. However, how cell compounds participate in the
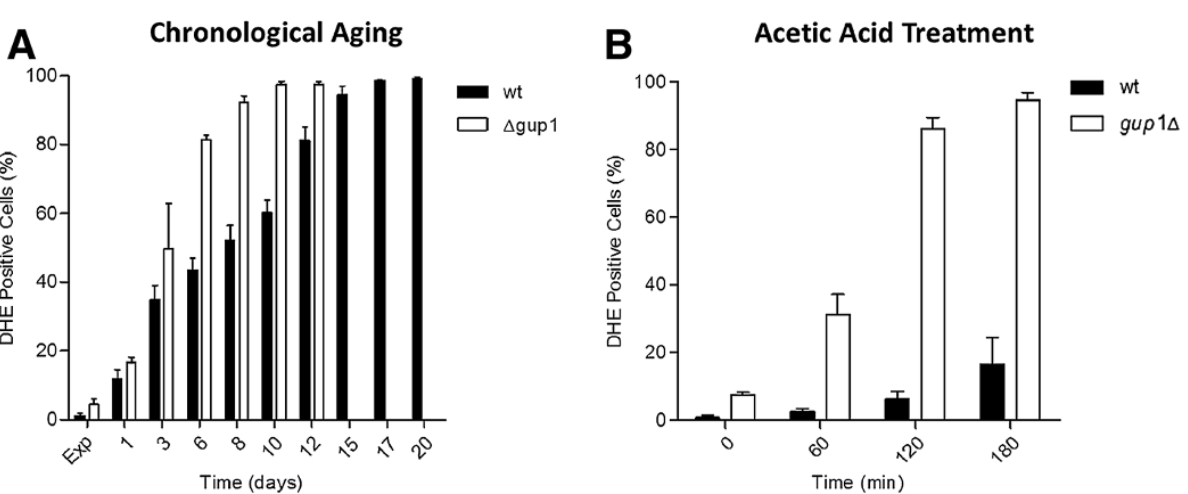

Figure 5 GUP1 deletion promotes substantial ROS accumulation. Cells from chronological lifespan assay (A) and from acetic acid treatment (B) were analyzed for accumulation of ROS using DHE staining by flow cytometry. At least 35,000 cells were analyzed. Data represent mean \pm SD of at least 3 independent experiments. 
processes leading to cell death in yeast remains to be established. Gup1p, an $O$-acyltransferase, is required for several cellular processes that are related to apoptosis development, namely, rafts integrity and stability, lipid metabolism including GPI anchor correct remodeling, proper mitochondrial and vacuole function, and actin dynamics [30,31,33,35,37,42,53-56].

In this work we used two known apoptosis-inducing conditions, chronological aging [6] and acetic acid [4], to assess several apoptotic markers in gup $1 \Delta$ mutant strain. We found that, when compared with Wt, gup1D mutant presents a significant reduced chronological lifespan, showing almost no viability after 11 days incubation. Chronologically aged yeast cultures were shown to die exhibiting typical apoptotic markers [6]. Accordingly, we showed that chronologically aged Wt cells predominantly commit to an apoptotic death, as revealed by a) PI negative cells; b) phosphatidylserine externalization; c) depolarization of mitochondrial membrane; and d) chromatin condensation. Yet, gup1 $1 \Delta$ mutant aged cells seem to be incapable of undergoing apoptosis. Instead, these cells appeared to be experiencing a necrotic cell death process. The gup1 $\Delta$ mutant aged culture exhibited a higher number of cells with loss of membrane integrity, and did not reveal an increase of phosphatidylserine exposure on the surface of the plasma membrane. Such observations discredit the possibility that these cells are dying through an apoptotic process, being more likely that the reduction in lifespan is due to a necrotic death. Furthermore, both loss of mitochondrial membrane potential and moderate chromatin condensation that we observed in this mutant have already been described in necrotic phenotypes [57,58]. Lately, several points of evidence suggest that necrotic cell death also occurs in yeast. Moreover, that can occur under normal physiological conditions or in the presence of cell death inducing substances, and not necessarily resulting from brutal chemical or physical damage, as previously thought [11].

We also used acetic acid as an apoptotic inducer of cell death in both Wt and gup $1 \Delta$ mutant strains. Our results revealed that acetic acid induces a cell death process similar to that observed in aging cultures. These results are in accordance with the hypothesis proposed in a previous work, in which the toxicity of acetic acid produced during aging was suggested as the major cause of chronological aging in yeast [59]. Reinforcing such idea are the acidified cultures that we observed during aging, probably resulting from acetic acid production and release to the medium (data not shown). Moreover, it was also reported that the signaling of acetic acid-induced apoptosis is linked to amino-acid metabolism as well as to the TOR pathway [60], as it happens in the aging process [61]. A necrotic death induced by acetic acid was already observed in other yeast mutants, namely in mutants in class C VPS genes that code for proteins essential for vacuolar and endossomal vesicle function [42].

Accumulation of ROS has predominantly been associated to yeast apoptosis under numerous conditions [62-64]. Some studies have addressed a fundamental role of ROS on the execution apoptotic death, after treatment with low doses of hydrogen peroxide [3] and on the superoxide-mediated altruistic program of aging [65]. Interestingly, however, many studies have suggested a crucial involvement of ROS during necrosis of mammalian cells [66] as well as in yeast necrosis [42,64]. This evidence is in accordance with our results. We observed a significant difference in ROS accumulation between Wt and gup1 $1 \Delta$ mutant strain in both chronological aging and acetic acid treatment. gup1 $1 \Delta$ mutant cells, which present a necrotic phenotype, have an extremely higher accumulation of ROS. If ROS can contribute, apart from its role on apoptosis, to the necrotic cell death in yeast as well, or if it is rather a byproduct that accumulates as a result of cellular demise, remains to be elucidated.

Gup1p has been described to have an important function on lipid rafts assembly/integrity [30]. In the literature, rafts have been increasingly implicated on regulation of apoptotic signaling in mammalian cells $[54,67]$. In response to intra or extracellular stimuli, lipid rafts can include or exclude proteins to variable extents. This favors specific protein-protein interactions and modulates the activity of signalling apoptotic cascades. Moreover, in mammalian cells a number of proteins involved in apoptotic signals have been found to locate in lipid rafts, namely Fas/CD95 receptor [68] and the pro-apoptotic protein of Bcl-2 family, Bad [69]. Our results showed that the PCD processes in S. cerevisiae is altered by GUP1 deletion and reinforce the importance of lipid rafts on the regulation of apoptotic signaling in yeast. Moreover, our findings point to that these membrane domains seem to be indispensable for a proper development of PCD, under aging and acetic acid conditions, namely in the switch from a necrotic to an apoptotic death phenotype.

\section{Conclusions}

We demonstrate that gup1 $1 \Delta$ mutant strain present a significantly reduced chronological lifespan comparing to Wt. Moreover, this mutant showed to be highly sensitive to acetic acid. Yet, while chronologically aged and acetic acid treated Wt cells die exhibiting apoptotic markers, gup1s mutant cells under the same conditions seems to be incapable of undergoing apoptosis. Instead, these cells appeared to be experiencing a necrotic cell death process. In addition, those cells also present extremely high levels of ROS. Being gup $1 \Delta$ mutant affected in lipid rafts integrity/assembly, lipid metabolism and GPI 
anchor remodeling we propose that the integrity of rafts may be essential for apoptosis induction and/or signaling. This provides for the first time the possible participation of lipid rafts in yeast apoptosis, giving new insights into the molecular mechanisms underlying this particular process of PCD, and highlighting the complex network of cellular structures that interact, cooperate and compete to regulate cell death.

\section{Methods}

\section{Strains and growth conditions}

The Saccharomyces cerevisiae strains used in this study were W303-1A [70] and BHY54 [32]. Yeast batch cultures were grown aerobically in minimal medium $(0.67 \%$ (wt/v) YNB (Difco)) with 2\% (wt/v) glucose and adequate quantities of auxotrophic requirements [71]. Incubation was performed at $30^{\circ} \mathrm{C}, 200 \mathrm{rpm}$, orbital shaking and air/ liquid ratio $3 / 1$. Yeast strains maintenance was done on rich medium (YPD (Difco) with $2 \%$ agar), grown at $30^{\circ} \mathrm{C}$ for $48 \mathrm{~h}$ and kept at $4^{\circ} \mathrm{C}$ up to 5 days.

\section{Chronological lifespan}

For chronological lifespan experiments, pre-inoculum cultures grown overnight on YNB were used to start batch cultures at $0.05\left(\mathrm{OD}_{600 \mathrm{~nm}}\right)$ in fresh YNB medium. At the stipulated time points, culture aliquots were taken to assess growth through $\mathrm{OD}_{600}$ and colony forming units (c.f.u.), and for apoptotic assays. c.f.u. were determined plating 1,000 cells, counted on a Neubauer chamber, on YPD agar, as previously described [6]. Colonies were counted after $48 \mathrm{~h}$ incubation at $30^{\circ} \mathrm{C}$. No further colonies appeared after that incubation period.

\section{Sensitivity to acetic acid}

Dropout tests were performed from mid-exponential YNB cultures containing approximately $1 \times 10^{6}$ cells $/ \mathrm{ml}$. Ten-fold serial dilutions were made, and $5 \mu \mathrm{l}$ of each suspension was applied on YNB medium supplemented with different acetic acid concentrations (50, 80 and 100 $\mathrm{mM})$. Results were scored after $48 \mathrm{~h}$ incubation at $30^{\circ} \mathrm{C}$.

\section{Acetic acid treatment}

Yeast strains were grown until exponential phase $\left(\mathrm{OD}_{600}\right.$ $=0.5-0.6)$ on YNB medium. Then the cultures were collected and resuspended to a final concentration of $10^{7}$ cells $\mathrm{ml}^{-1}$ in fresh YNB adjusted to $\mathrm{pH} 3.0$ with $\mathrm{HCl}$ and containing $160 \mathrm{mM}$ acetic acid. Incubation took place for $180 \mathrm{~min}$ at $30^{\circ} \mathrm{C}$ as previously described [4,72]. At determined time points, $40 \mu \mathrm{l}$ from a $10^{-4}$ cell suspension were inoculated onto YPD agar plates and c.f.u. were counted after $48 \mathrm{~h}$ incubation at $30^{\circ} \mathrm{C}$. The percentage of viable cells was estimated considering $100 \%$ survival the number of c.f.u. obtained in time 0 .

\section{Apoptotic markers}

PI, Annexin V, DAPI and $\mathrm{DiOC}_{6}$ staining were performed both in cells treated with acetic acid and in aging cells as previously described, with some modifications $[1,3,4,37]$.

Membrane integrity was assessed by PI (Propidium Iodide) staining. Cells were harvested, washed and resuspended in PBS $(137 \mathrm{mM} \mathrm{NaCl} ; 2.7 \mathrm{mM} \mathrm{KCl} ; 100 \mathrm{mM}$ $\left.\mathrm{Na}_{2} \mathrm{HPO}_{4} ; 2 \mathrm{mM} \mathrm{K} \mathrm{H}_{2} \mathrm{PO}_{4} ; \mathrm{pH} 7.4\right)$ containing PI $(4 \mu \mathrm{g} /$ $\mathrm{ml}$ ) (Sigma). The samples were incubated for $10 \mathrm{~min}$ at room temperature in the dark and analyzed in an Epics ${ }^{\circ}$ $\mathrm{XL}^{\mathrm{ru}}$ (Beckman Coulter) flow cytometer. At least 20,000 cells from each sample were analyzed.

Phosphatidylserine exposure was detected by an FITCcoupled Annexin V reaction with the ApoAlertAnnexin $\mathrm{V}$ Apoptosis Kit (CLONTECH Laboratories). For that, cells were primarily harvested and washed in digesting buffer (1.2 M sorbitol; $0.5 \mathrm{mM} \mathrm{MgCl} 2 ; 35 \mathrm{mM} \mathrm{K}_{2} \mathrm{HPO}_{4}$; $\mathrm{pH}$ 6.8). To promote the drug course through cell wall, an incubation step with Zymolyase $(20 \mathrm{~T})$ at $30^{\circ} \mathrm{C}$ was performed. Phase-contrast microscopy was used to monitor that step, preventing this way damage to the unfixed spheroplasts. Cells were subsequently centrifuged $(10 \mathrm{~min}$ at $1500 \mathrm{rpm})$ and resuspended in $200 \mu \mathrm{l}$ of binding buffer (1.2 M sorbitol; $10 \mathrm{mM}$ HEPES/NaOH, $\mathrm{pH} 7.4 ; 140 \mathrm{mM} \mathrm{NaCl} ; 2.5 \mathrm{mM} \mathrm{Cacl} 2)$. To $40 \mu \mathrm{l}$ of this cell suspension, $2 \mu \mathrm{l}$ Annexin $\mathrm{V}(1 \mu \mathrm{g} / \mathrm{ml})$ and $1 \mu \mathrm{l}$ PI $(4$ $\mu \mathrm{g} / \mathrm{ml}$ ) were added, and the mixture incubated for 20 $\mathrm{min}$ at room temperature in the dark. Finally, extra 400 $\mu \mathrm{l}$ of binding buffer were added to the mixture just prior to analysis in an Epics ${ }^{\circ} \mathrm{XL}^{\mathrm{Tm}}$ (Beckman Coulter) flow cytometer. At least 20,000 cells from each sample were analyzed.

For evaluation of mitochondrial potential the probe $\mathrm{DiOC}_{6}$ (3,3' dihexyloxacarbocyanine iodide) (Invitrogen) was used. Cells were harvested, washed, and resuspended in $\mathrm{DiOC}_{6}$ buffer (10 mM MES; $0.1 \mathrm{mM} \mathrm{MgCl} 2 ; 2 \%$ (wt/ v) glucose, adjusted to $\mathrm{pH} 6$ set with $\mathrm{Ca}(\mathrm{OH})_{2}$ ) containing $\mathrm{DiOC}_{6}(20 \mathrm{ng} / \mathrm{ml})$. Cells were visualized by light microscopy (LM) after $30 \mathrm{~min}$ at room temperature in the dark. At least, 300 cells selected randomly were counted per sample. The number of cells counted with mitochondrial depolarization (cells without fluorescence) was indexed to our $100 \%$ (300 cells).

Chromatin condensation was assessed by DAPI $(4,6-$ diamino-2-phenylindole dihydrochloride) (Sigma) staining. Cells were harvested, washed, fixed for $45 \mathrm{~min}$ with $3.7 \%$ formaldehyde, permeabilized with a solution of $70 \%$ $(\mathrm{v} / \mathrm{v})$ ethanol for $30 \mathrm{~min}$, sonicated for $5 \mathrm{sec}$ and afterwards stained with DAPI $(1 \mu \mathrm{g} / \mathrm{ml})$. Cells were visualized by LM after $5 \mathrm{~min}$ at room temperature in the dark. At least 300 cells selected randomly were counted per sample. The number of cells counted with chromatin condensation was indexed to our 100\% (300 cells). 
Stained cells were visualized in a Leica Microsystems DM-5000B epifluorescence microscope with appropriate filter settings using a $100 \times$ oil-immersion objective. Images were acquired with a Leica DCF350FX digital camera and processed with LAS AF Leica Microsystems software.

\section{Assessment of ROS}

To visualize accumulation of ROS cells were harvested by centrifugation, resuspended in PBS in the presence of DHE (Dihydroethidium) $(4 \mu \mathrm{g} / \mathrm{ml})$, and further incubated in the dark for $30 \mathrm{~min}$ at room temperature. To quantify the number of cells displaying high ROS levels, at least 20,000 cells were counted in an Epics ${ }^{\ominus} \mathrm{XL}^{\mathrm{Tm}}$ (Beckman Coulter) flow cytometer.

\section{Authors' contributions}

JT and FF-O carried out the experimental studies, having contributed 75\% and $25 \%$ respectively. CF supervised JT and FF-O and checked the data. JT and $C F$ wrote this manuscript. $C L$ revised the manuscript. All authors read and approved the final manuscript.

\section{Acknowledgements}

This work was supported by FEDER funds through the COMPETE (Programa Operacional Factores de Competitividade) and national funds through FCT (Fundação para a Ciência e a Tecnologia) through FCOMP-01-0124-FEDER07047. Fábio Faria-Oliveira is a PhD grantee from FCT (SFRH/BD/45368/2008) Authors would like to acknowledge Manuela Côrte-Real for profitable discussions of the results and to Rui Silva for assistance on cytometry experiments. We also thank Hugh S. Johnson for the critical reading of the manuscript regarding English usage.

\section{Received: 23 December 2011 Accepted: 27 April 2012}

Published: 22 May 2012

\section{References}

1. Madeo F, Frohlich E, Frohlich KU: A yeast mutant showing diagnostic markers of early and late apoptosis. J Cell Biol 1997, 139(3):729-734.

2. Ligr M, Madeo F, Frohlich E, Hilt W, Frohlich KU, Wolf DH: Mammalian Bax triggers apoptotic changes in yeast. FEBS Lett 1998, 438(1-2):61-65.

3. Madeo F, Frohlich E, Ligr M, Grey M, Sigrist SJ, Wolf DH, Frohlich KU: Oxygen stress: a regulator of apoptosis in yeast. J Cell Biol 1999, 145(4):757-767.

4. Ludovico P, Sousa MJ, Silva MT, Leao C, Corte-Real M: Saccharomyces cerevisiae commits to a programmed cell death process in response to acetic acid. Microbiology 2001, 147(Pt 9):2409-2415.

5. Frohlich KU, Fussi H, Ruckenstuhl C: Yeast apoptosis-from genes to pathways. Semin Cancer Biol 2007, 17(2):112-121.

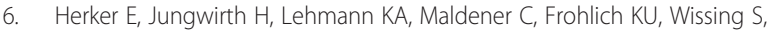
Buttner S, Fehr M, Sigrist S, Madeo F: Chronological aging leads to apoptosis in yeast. J Cell Biol 2004, 164(4):501-507.

7. Vachova L, Palkova Z: Physiological regulation of yeast cell death in multicellular colonies is triggered by ammonia. J Cell Biol 2005, 169 (5):711-717.

8. Madeo F, Herker E, Wissing S, Jungwirth $H$, Eisenberg T, Frohlich KU: Apoptosis in yeast. Curr Opin Microbiol 2004, 7(6):655-660.

9. Madeo F, Herker E, Maldener C, Wissing S, Lachelt S, Herlan M, Fehr M, Lauber K, Sigrist SJ, Wesselborg S, et al: A caspase-related protease regulates apoptosis in yeast. Mol Cell 2002, 9(4):911-917.

10. Wissing S, Ludovico P, Herker E, Buttner S, Engelhardt SM, Decker T, Link A, Proksch A, Rodrigues F, Corte-Real M, et al: An AIF orthologue regulates apoptosis in yeast. J Cell Biol 2004, 166(7):969-974

11. Buttner S, Eisenberg T, Carmona-Gutierrez D, Ruli D, Knauer H, Ruckenstuhl C, Sigrist C, Wissing S, Kollroser M, Frohlich KU, et al: Endonuclease G regulates budding yeast life and death. Mol Cell 2007, 25(2):233-246.
12. Fahrenkrog B, Sauder U, Aebi U: The S. cerevisiae HtrA-like protein Nma111p is a nuclear serine protease that mediates yeast apoptosis. J Cell Sci 2004, 117(Pt 1):115-126.

13. Walter D, Wissing S, Madeo F, Fahrenkrog B: The inhibitor-of-apoptosis protein Bir1p protects against apoptosis in S. cerevisiae and is a substrate for the yeast homologue of Omi/HtrA2. J Cell Sci 2006, 119(Pt 9):1843-1851.

14. Buttner S, Ruli D, Vogtle FN, Galluzzi L, Moitzi B, Eisenberg T, Kepp O, Habernig L, Carmona-Gutierrez D, Rockenfeller $\mathrm{P}$, et al: A yeast $\mathrm{BH}$-only protein mediates the mitochondrial pathway of apoptosis. EMBO J 2011, 30(14):2779-2792.

15. Saraiva L, Silva RD, Pereira G, Goncalves J, Corte-Real M: Specific modulation of apoptosis and $\mathrm{BCl}-\mathrm{xL}$ phosphorylation in yeast by distinct mammalian protein kinase C isoforms. J Cell Sci 2006, 119(Pt 15):3171-3181.

16. Kaeberlein M: Longevity and aging in the budding yeast. In In: Handbook of models for human aging. Edited by Conn PM. San Diego: Academic; 2006.

17. Laun P, Ramachandran L, Jarolim S, Herker E, Liang P, Wang J, Weinberger M, Burhans DT, Suter B, Madeo F, et al: A comparison of the aging and apoptotic transcriptome of Saccharomyces cerevisiae. FEMS Yeast Res 2005, 5(12):1261-1272.

18. Aerts AM, Zabrocki P, Francois IE, Carmona-Gutierrez D, Govaert G, Mao C, Smets B, Madeo F, Winderickx J, Cammue BP, et al: Ydc1p ceramidase triggers organelle fragmentation, apoptosis and accelerated ageing in yeast. Cell Mol Life Sci 2008, 65(12):1933-1942.

19. Carmona-Gutierrez D, Reisenbichler A, Heimbucher P, Bauer MA, Braun RJ, Ruckenstuhl C, Buttner S, Eisenberg T, Rockenfeller P, Frohlich KU, et al: Ceramide triggers metacaspase-independent mitochondrial cell death in yeast. Cell Cycle 2011, 10(22):3973-3978.

20. Barbosa AD, Osorio H, Sims KJ, Almeida T, Alves M, Bielawski J, Amorim MA, Moradas-Ferreira P, Hannun YA, Costa V: Role for Sit4p-dependent mitochondrial dysfunction in mediating the shortened chronological lifespan and oxidative stress sensitivity of Isc1p-deficient cells. Mol Microbiol 2011, 81(2):515-527.

21. Almeida $T$, Marques $M$, Mojzita D, Amorim MA, Silva RD, Almeida $B$, Rodrigues $\mathrm{P}$, Ludovico P, Hohmann S, Moradas-Ferreira P, et al: Isc1p plays a key role in hydrogen peroxide resistance and chronological lifespan through modulation of iron levels and apoptosis. Mol Biol Cell 2008, 19 (3):865-876.

22. Ogretmen $B$, Hannun $Y A$ : Biologically active sphingolipids in cancer pathogenesis and treatment. Nat Rev Cancer 2004, 4(8):604-616.

23. Thevissen K, Francois IE, Winderickx J, Pannecouque C, Cammue BP: Ceramide involvement in apoptosis and apoptotic diseases. Mini Rev Med Chem 2006, 6(6):699-709.

24. Jacobson K, Mouritsen OG, Anderson RG: Lipid rafts: at a crossroad between cell biology and physics. Nat Cell Biol 2007, 9(1):7-14

25. Bagnat $M$, Keranen $S$, Shevchenko A, Simons K: Lipid rafts function in biosynthetic delivery of proteins to the cell surface in yeast. Proc Natl Acad Sci U S A 2000, 97(7):3254-3259.

26. Alvarez-Vasquez F, Sims KJ, Voit EO, Hannun YA: Coordination of the dynamics of yeast sphingolipid metabolism during the diauxic shift. Theor Biol Med Model 2007, 4:42.

27. Pittet $M$, Conzelmann A: Biosynthesis and function of GPI proteins in the yeast Saccharomyces cerevisiae. Biochim Biophys Acta 2007, 1771(3):405-420.

28. Hofmann K: A superfamily of membrane-bound O-acyltransferases with implications for wnt signaling. Trends Biochem Sci 2000, 25(3):111-112.

29. Neves L, Oliveira R, Lucas C: Yeast orthologues associated with glycerol transport and metabolism. FEMS Yeast Res 2004, 5(1):51-62.

30. Ferreira C, Lucas C: The yeast O-acyltransferase Gup1p interferes in lipid metabolism with direct consequences on the sphingolipid-sterol-ordered domains integrity/assembly. Biochim Biophys Acta 2008, 1778(11):2648-2653.

31. Bosson R, Jaquenoud M, Conzelmann A: GUP1 of Saccharomyces cerevisiae encodes an O-acyltransferase involved in remodeling of the GPI anchor. Mol Biol Cell 2006, 17(6):2636-2645.

32. Holst B, Lunde C, Lages F, Oliveira R, Lucas C, Kielland-Brandt MC: GUP1 and its close homologue GUP2, encoding multimembrane-spanning proteins involved in active glycerol uptake in Saccharomyces cerevisiae. Mol Microbiol 2000, 37(1):108-124.

33. Ferreira C, Silva S, van Voorst F, Aguiar C, Kielland-Brandt MC, Brandt A Lucas C: Absence of Gup1p in Saccharomyces cerevisiae results in defective cell wall composition, assembly, stability and morphology. FEMS Yeast Res 2006, 6(7):1027-1038. 
34. Oelkers P, Tinkelenberg A, Erdeniz N, Cromley D, Billheimer JT, Sturley SL: A lecithin cholesterol acyltransferase-like gene mediates diacylglycerol esterification in yeast. J Biol Chem 2000, 275(21):15609-15612.

35. Ni L, Snyder M: A genomic study of the bipolar bud site selection pattern in Saccharomyces cerevisiae. Mol Biol Cell 2001, 12(7):2147-2170.

36. Askree SH, Yehuda T, Smolikov S, Gurevich R, Hawk J, Coker C, Krauskopf A, Kupiec M, McEachern MJ: A genome-wide screen for Saccharomyces cerevisiae deletion mutants that affect telomere length. Proc Natl Acad Sci U S A 2004, 101(23):8658-8663.

37. Gourlay CW, Ayscough KR: Identification of an upstream regulatory pathway controlling actin-mediated apoptosis in yeast. J Cell Sci 2005, 118(Pt 10):2119-2132.

38. Qi H, Li TK, Kuo D, Nur EKA, Liu LF: Inactivation of Cdc13p triggers MEC1dependent apoptotic signals in yeast. J Biol Chem 2003, 278(17):15136-15141.

39. Carmona-Gutierrez D, Jungwirth H, Eisenberg T, Madeo F: Cell cycle control of cell death in yeast. Cell Cycle 2010, 9(20):4046.

40. Fabrizio P, Longo VD: The chronological life span of Saccharomyces cerevisiae. Aging Cell 2003, 2(2):73-81

41. Rockenfeller P, Madeo F: Apoptotic death of ageing yeast. Exp Gerontol 2008, 43(10):876-881.

42. Schauer A, Knauer H, Ruckenstuhl C, Fussi H, Durchschlag M, Potocnik U, Frohlich KU: Vacuolar functions determine the mode of cell death. Biochim Biophys Acta 2009, 1793(3):540-545.

43. Cerbon J, Calderon V: Changes of the compositional asymmetry of phospholipids associated to the increment in the membrane surface potential. Biochim Biophys Acta 1991, 1067(2):139-144.

44. Martin SJ, Reutelingsperger CP, McGahon AJ, Rader JA, van Schie RC, LaFace DM, Green DR: Early redistribution of plasma membrane phosphatidylserine is a general feature of apoptosis regardless of the initiating stimulus: inhibition by overexpression of $\mathrm{BCl}-2$ and $\mathrm{Abl}$. J Exp Med 1995, 182(5):1545-1556.

45. Pichova A, Vondrakova D, Breitenbach M: Mutants in the Saccharomyces cerevisiae RAS2 gene influence life span, cytoskeleton, and regulation of mitosis. Can J Microbiol 1997, 43(8):774-781.

46. Laun P, Pichova A, Madeo F, Fuchs J, Ellinger A, Kohlwein S, Dawes I, Frohlich KU, Breitenbach M: Aged mother cells of Saccharomyces cerevisiae show markers of oxidative stress and apoptosis. Mol Microbiol 2001, 39(5):1166-1173.

47. Ludovico P, Rodrigues F, Almeida A, Silva MT, Barrientos A, Corte-Real M: Cytochrome $c$ release and mitochondria involvement in programmed cell death induced by acetic acid in Saccharomyces cerevisiae. Mol Biol Cell 2002, 13(8):2598-2606.

48. Longo VD, Gralla EB, Valentine JS: Superoxide dismutase activity is essential for stationary phase survival in Saccharomyces cerevisiae. Mitochondrial production of toxic oxygen species in vivo. $J \mathrm{Bio} / \mathrm{Chem}$ 1996, 271(21):12275-12280

49. Nestelbacher R, Laun P, Vondrakova D, Pichova A, Schuller C, Breitenbach M: The influence of oxygen toxicity on yeast mother cell-specific aging. Exp Gerontol 2000, 35(1):63-70.

50. Buttner S, Eisenberg T, Herker E, Carmona-Gutierrez D, Kroemer G, Madeo F: Why yeast cells can undergo apoptosis: death in times of peace, love, and war. J Cell Biol 2006, 175(4):521-525.

51. Fleury C, Pampin M, Tarze A, Mignotte B: Yeast as a model to study apoptosis? Biosci Rep 2002, 22(1):59-79.

52. Madeo F, Engelhardt S, Herker E, Lehmann N, Maldener C, Proksch A Wissing S, Frohlich KU: Apoptosis in yeast: a new model system with applications in cell biology and medicine. Curr Genet 2002, 41(4):208-216

53. Dickson RC, Lester RL: Sphingolipid functions in Saccharomyces cerevisiae. Biochim Biophys Acta 2002, 1583(1):13-25.

54. Garcia A, Cayla X, Fleischer A, Guergnon J, Alvarez-Franco Canas F, Rebollo MP, Roncal F, Rebollo A: Rafts: a simple way to control apoptosis by subcellular redistribution. Biochimie 2003, 85(8):727-731.

55. Pereira C, Silva RD, Saraiva L, Johansson B, Sousa MJ, Corte-Real M: Mitochondria-dependent apoptosis in yeast. Biochim Biophys Acta 2008, 1783(7):1286-1302.

56. dos Santos SC, Sa-Correia I: Genome-wide identification of genes required for yeast growth under imatinib stress: vacuolar $\mathrm{H}+-$ ATPase function is an important target of this anticancer drug. OMICS 2009, 13(3):185-198.

57. Galluzzi L, Maiuri MC, Vitale I, Zischka H, Castedo M, Zitvogel L, Kroemer G: Cell death modalities: classification and pathophysiological implications. Cell Death Differ 2007, 14(7):1237-1243.
58. Sripriya P, Vedantam LV, Podile AR: Involvement of mitochondria and metacaspase elevation in harpin Pss-induced cell death of Saccharomyces cerevisiae. J Cell Biochem 2009, 107(6):1150-1159.

59. Burtner CR, Murakami CJ, Kennedy BK, Kaeberlein M: A molecular mechanism of chronological aging in yeast. Cell Cycle 2009, 8(8):1256-1270.

60. Almeida B, Ohlmeier S, Almeida AJ, Madeo F, Leao C, Rodrigues F, Ludovico $P$ : Yeast protein expression profile during acetic acid-induced apoptosis indicates causal involvement of the TOR pathway. Proteomics 2009, 9 (3):720-732.

61. Powers RW 3rd, Kaeberlein M, Caldwell SD, Kennedy BK, Fields S: Extension of chronological life span in yeast by decreased TOR pathway signaling. Genes Dev 2006, 20(2):174-184.

62. Pozniakovsky Al, Knorre DA, Markova OV, Hyman AA, Skulachev VP, Severin FF: Role of mitochondria in the pheromone- and amiodarone- induced programmed death of yeast. J Cell Biol 2005, 168(2):257-269.

63. Braun RJ, Zischka H, Madeo F, Eisenberg T, Wissing S, Buttner S, Engelhardt SM, Buringer D, Ueffing M: Crucial mitochondrial impairment upon CDC48 mutation in apoptotic yeast. J Biol Chem 2006, 281(35):25757-25767.

64. Eisenberg $T$, Buttner $S$, Kroemer G, Madeo F: The mitochondrial pathway in yeast apoptosis. Apoptosis 2007, 12(5):1011-1023.

65. Fabrizio P, Battistella L, Vardavas R, Gattazzo C, Liou LL, Diaspro A, Dossen JW, Gralla EB, Longo VD: Superoxide is a mediator of an altruistic aging program in Saccharomyces cerevisiae. J Cell Biol 2004, 166(7):1055-1067.

66. Festjens $N$, Vanden Berghe $T$, Vandenabeele P: Necrosis, a wellorchestrated form of cell demise: signalling cascades, important mediators and concomitant immune response. Biochim Biophys Acta 2006, 1757(9-10):1371-1387.

67. Mollinedo F, Gajate C: Lipid rafts and clusters of apoptotic signaling molecule-enriched rafts in cancer therapy. Future Oncol 2010, 6(5):811-821.

68. Gajate C, Mollinedo F: The antitumor ether lipid ET-18-OCH(3) induces apoptosis through translocation and capping of Fas/CD95 into membrane rafts in human leukemic cells. Blood 2001, 98(13):3860-3863.

69. Ayllon V, Fleischer A, Cayla X, Garcia A, Rebollo A: Segregation of Bad from lipid rafts is implicated in the induction of apoptosis. J Immuno/ 2002, 168(7):3387-3393.

70. Thomas BJ, Rothstein R: Elevated recombination rates in transcriptionally active DNA. Cell 1989, 56(4):619-630.

71. Sherman F: Getting started with yeast. Methods Enzymol 2002, 350:3-41.

72. Guaragnella N, Pereira C, Sousa MJ, Antonacci L, Passarella S, Corte-Real M, Marra E, Giannattasio S: YCA1 participates in the acetic acid induced yeast programmed cell death also in a manner unrelated to its caspase-like activity. FEBS Lett 2006, 580(30):6880-6884.

doi:10.1186/1471-2180-12-80

Cite this article as: Tulha et al:: Programmed cell death in Saccharomyces cerevisiae is hampered by the deletion

of GUP1 gene. BMC Microbiology 2012 12:80.

\section{Submit your next manuscript to BioMed Central and take full advantage of:}

- Convenient online submission

- Thorough peer review

- No space constraints or color figure charges

- Immediate publication on acceptance

- Inclusion in PubMed, CAS, Scopus and Google Scholar

- Research which is freely available for redistribution 